INTERNATIONAL JOURNAL OF MULTIDisciplinARY RESEARCH AND ANALYSis

ISSN(print): 2643-9840, ISSN(online): 2643-9875

Volume 05 Issue 03 March 2022

DOI: 10.47191/ijmra/v5-i3-01, Impact Factor: 6.072

Page No. 586-590

\title{
On the Identity Construction and Industrial Development of "Digital Self-Maker" In Online Sales in the Digital Age
}

\author{
Liu Yongliang \\ Silpakorn University, Anhui Art College
}

\begin{abstract}
With the development of network and digital technology, modern business began to turn to online sales. Relying on digital technology, database technology and Internet of Things (IoT) technology, virtual online store has changed people's patterns of behavior, thinking and aesthetic. In the virtual network community, "Makers" are dominated by desktop transactions. According to the demands and evaluations of customers, "Digital Maker" began to transform technology, management experience, artistic design, their own mindsets and literacy, so as to advance the development of the whole network market and industrial economy.
\end{abstract}

KEY WORDS: Digital age; Digital Maker; Network sales; Industrial economy; design

The development of network digital technology has brought a new production model of batch and standardization of modern industry, which not only saves costs, but also optimizes industrial resources. However, time and people's pursuit of personalization and diversification results to mass production model gradually shows its disadvantages. With the advent of digital economy, digital technology has incubated a new business model which rely on the development of network technology, big data technology and loT technology. For producers, they communicate and interact with consumers in the online community in order to transform into the identity of "Digital Maker" by understanding the needs of consumers, creating personalized goods and changing the operation mechanism. Besides, the application of "Digital Maker" has also sprung up in European and American countries because of the progress of modern industry and computer technology. "In the self-made movement, it is very important to do it yourself, but the past 'self-made' behavior is often limited by some technology factors such as the backwardness of manufacturing tools, the lack of design aesthetics, the limitation of information sharing and so on." ${ }^{[1]}$ Last, profiting from information technology, many producers began to improve their self-study ability and professional quality to meet the commercial needs of the society. The commercial space in the digital age has turned to virtual online stores. For both consumers and producers, it is in the transaction and interaction of goods that an experience economy model is formed. Therefore, at this time, the subjectivity of the self-made identity is gradually replaced by a creative and experiential sharing economy.

\section{CURRENT SITUATION OF NETWORK SALES IN THE DIGITAL AGE}

Since the 1980s, digital technology and network technology has brought unprecedented challenges to China's traditional industry. At the same time, digital technology provides the innovation of "Digital Maker" thinking for modern industry, and forms a new operation model within the context of digital technology. The mass production in the era of large industry makes the symbolic value substitutes for the functional value, which inevitably causes personal handicrafts be compressed to the lowest. Afterdigital technology entering modern industry, a group of "Makers" familiar with table production appeared in the process of production and sales of goods. These "Makers" are equipped with creativity and craftsmanship. They also have the spirit of cooperation and are good at paying attention to communicating with customers in the online community. At this time, the production model of goods has been transformed into a sharing economy, and the value of goods has also turned to the production model with experience value. The rising numerical control technology and rapid prototyping technology have also brought an unprecedented leap to the development of modern industry. The production of modern industrial products can not only complete the display of 


\section{On the Identity Construction and Industrial Development of "Digital Self-Maker" In Online Sales in the Digital Age}

renderings or animation scenes through the setting of product models and scenes and parameters by computer software, but also investigate the sales volume and sales channels of products according to the big data statistics of computer network. The "Maker" can utilize digital tools to finish the product design on the screen, and improve the technology and products according to the requirements of consumers at any time. It provides an electronic database for preview through virtual imaging technology, and digitizes some traditional industrial production skills through computer network media.

Network technology has brought a new way of communication and display for the evolution of modern industrial products. By using digital technology, special industrial products can be classified and displayed on the Internet through fixed portal websites. Through the numbering and sorting of the database, people can easily retrieve the electronic data of the picture database or image database. Regarding the digital presentation of industrial products as the original database, we can process and modify the original data online, recreate it, and then create more creative industrial products to meet the modern people's lifestyle. The information of traditional industries can be quickly spread on the digital community platform, and can be produced and sold on the table. For consumers, they first buy virtual digital images, and then be serviced by offline delivery through loT technology.

In recent years, online stores have been gradually improved. Firstly, the construction of digital network can level the channel of network information dissemination for modern online stores and form data analysis through network data. For some businesses, they can choose different network platforms to carry out network e-commerce. You can register stores, decorate stores, display products online, complete commodity transaction payment and message evaluation, etc. Secondly, the express industry thrives. The early express steel industry mainly receives orders offline. With the development of Internet technology, many express companies moved to the Internet and combined with relevant platforms for bundle sales. Then, receiving points are established in the residential community, with the emergence of post stations, hives and other forms, so that online and offline are connected together to form a closed loT system; Thirdly, the maturity of online banking, rapid payment and QR code technology enable online stores to form a scale basically. Early online stores mainly paid on delivery, but in the wake of the improvement of online store payment system and reputation, there are now various forms of direct payment, trial period, evaluation and reward, which makes the online store system more complete and wins stronger credibility among consumers, sales platforms and producers; Fourth, new media communication has improved the speed of online commodity circulation. In the early stage of marketing, the main way is to build sales websites and enter specific sales websites for consumption and shopping. Thankfully, now there are professional apps. People can create industry characteristics and establish brand effect through professional apps. For example, Tik Tok, Taobao, WeChat, QQ, jitter, and Kwai provide platforms for live-streaming scales. All of these can accelerate the progress of commercial selling.

\section{THE CONSTRUCTION OF THE IDENTITY OF "MAKER" IN THE DIGITAL AGE}

On the outset, the creation task and value of the "Maker" will be explained. At the end of the 20th century, the "Digital Maker" movement caused the exploration of Open Source. Intellectual property rights were formed with "Maker's" own value in the process of opening source code of some computer software. In particular, the generation of big data and huge amount of information makes the computer micro control system penetrate into our daily life. For "self-made people", we should first master digital technology for desktop production, and then form a kind of digital manufacturing in the virtual network community. "Digital manufacturing is constituted by the integration of digital technology and manufacturing technology. With the support of virtual reality, computer network, rapid prototyping, database and other technologies, it analyzes, plans and reorganizes product information, process information and resource information according to the needs of users, so as to realize the simulation of product design, function and prototype manufacturing, to quickly produce products that can meet the requirements of users." [2]The "Makers'" main tasks are DIY, sharing, communication, desktop manufacturing and creative transformation. The "Maker" mainly tells everyone through the online community what the "Maker" should do, including the tools used by them. They have responsibilities to take into account the culture of consumers, so as to integrate people's needs and finally form the possibility of business model. Digital technology creates economic possibilities through contemporary network platforms with different knowledge, technologies and survival instincts, which expresses contemporary humanistic values.

As the embodiment of economic value, "Maker" should use the network platform to understand the current situation of the market and marketing of their own works and pay attention to the comparative relationship between different producers through 


\section{On the Identity Construction and Industrial Development of "Digital Self-Maker" In Online Sales in the Digital Age}

the statistics of big data and cloud computing. In the sales of products, the loT uses network technology to connect all things, collect and analyze consumer behavior through digital devices, cloud links, big data analysis and intelligent decision-making, and promote sales by innovating services and reversing the traditional management mode. "Digital Maker" is the practitioner who master new technology and maintain the development of network business economy. Digital technology provides "Digital Maker" with online sales information at the same time. The development of IoT technology has realized the development of information industrialization because loT technology combines online information and online operation through information technology, remote management control and intelligent management, and realizes the connection between people and objects, objects and objects. With the development of digital technology, loT, vehicle app and sales model, the network market economy has gradually built a new economic law in the network era.

The second one is the formation of "Digital Maker" identity in virtual network community. The development of science and digital technology has brought the Tool Revolution to the whole socio-economic form. The modern capitalist industrial economy brings new opportunities to modern craftsmen, and creates friendly atmosphere for the "Maker" in the era of network economy. The advent of the digital age provides a broader platform and living space for "Maker". Makers mainly complete tasks through desktop manufacturing, which is intelligent and creative relying on mental labor. In modern venture capital design, the perfect products are not only determined by function and appearance, but also the creative communication and experience process in the network. Modern product design is an assembly centered on humanistic design. Through the trend of design, we can find out what the most important needs of ordinary users and consumers are. After the handicrafts that people need are created on the digital platform, the "Maker" will help consumers solve problems, rather than imposing the products on consumers based on the "Maker's" own experience. As the "Digital Maker" of modern industry, we should understand the production line of modern industry and complete the new design according to the requirements of customers. As a manufacturer of modern industry, how to control the imagination of consumers, to create an "identity", and then to manufacture the products needed by the society through connection and communication? This requires modern industrial producers to improve their artistic literacy, their technological skills and proficiency, to change the identity and creative concept of "Digital Maker". "Digital literacy includes the ability to discover, organize and process information, the application ability of computer software. It mainly focuses on the digital field. Steam literacy and maker literacy acquire knowledge and cultivate ability by hand, but steam literacy is more focused on technology and engineering. The scope of maker literacy is broader, and it has no provision to master some discipline knowledge but pay close attention to the development of personal innovation. "[3]

It can be seen that with the advent of the era of digital economy, social design based on big data and "Digital Maker" spirit seems to have begun to penetrate into the whole social culture. As "Makers" in the new era, we should digitize our creative ideas through the Internet, and enriches our creativity through sharing in the online community. Digital technology not only provides economic value for the contemporary industrial products, but also expands the space of market and the approaches of marketing. In the agricultural era, handmade has become the main way of production. In the industrial and post-industrial age, alienation arises among people, and the subjectivity of self-made people gradually disappears.

\section{EXPLORATION OF THE DEVELOPMENT OF INDUSTRIAL ECONOMY IN THE ERA OF "MAKER"}

First of all, the "Maker" is the creator based on the virtual digital economy. First, as a "Maker", we should not only understand and master advanced science and technology, but also have the ability to find and solve problems. Chris Anderson put forward the concept of "Maker". In his opinion, "Digital Maker" is a customer-centered personal design and personal manufacturing, which is to pursue the realization of their own creative value. As a "Maker", we should not only have basic practical ability, but also are able to use new technology to finish creation. Only in this way can the products become innovative and creative. Second, as a "Maker", we should also have the ability of communication, cooperation and sharing. "Maker" should be capable of teamwork and handling the relationship with the team, peer competitors, customers and consumers in the virtual online consumption environment. "Makers" share their own creative ideas and exchange creative products on the maker's community platform both online and offline. On the one hand, we can cater to the personalized needs of consumers through interactive communication with high quality and low price; On the other hand, producers can improve their capacity to ensure their products meet the needs of society. Third, as "Makers", we should accept new things actively, firmly establish a sense of service, critical spirit and persistent craftsman 


\section{On the Identity Construction and Industrial Development of "Digital Self-Maker" In Online Sales in the Digital Age}

spirit. "Makers" maintain the awareness of innovation in commodity production. They learn spontaneously, master new technologies, new materials and new processes, and cater to clients initiatively. Moreover, establish a critical consciousness in the production of goods and listen to advice are also necessary. Evaluation in online sales is a method to improve the quality of products through consumer information feedback, which helps construct a competitive mechanism. In the live-streaming sales, it fully reflects the values of consumers that sellers improve their service awareness according to the concept of consumers preference. Consumers' imagination of products is experienced in the online community. Consumers' consumption process and products themselves become a part of their life so that wealth and goods become the representation of their identity and culture. Therefore, consumers get psychological and spiritual recognition, and the economic value in online sales can be reflected.

Secondly, the "Digital Maker" has gathered the collective wisdom in the online community, thus forming the experience economy model of "Digital Maker" production. In the process of commodity production, the "Digital Maker" needs to listen to the opinions of consumers, learn the knowledge of others, and pay attention to all kinds of messages and interactions. At this time, the "Digital Maker" and consumers, combined with the public message database, form an interactive, pluralistic and symbiotic network system. The process of commodity production is equivalent to a process of collective experience. In the online store, there are not only product introduction, but also store decoration, various information dialog boxes and electronic posters. Customers can experience virtual products in online stores. "The economic model in the era of digital reproduction pays more attention to satisfying the sensory experience of the body, and then into the experience of human emotion and spirit. In the display of modern digital art, the audience can shuttle back and forth and gallop freely in the space-time dimensions of different logic, such as history and future, material and spirit, emotion and reason." ${ }^{[4]}$ For the "Maker", the task is to give commodity new meaning and higher symbolic value, so as to change the relationship between consumers and goods and enhance the experience value of "things". In the community platform of modern loT, "Makers" strengthen the construction of "things" in people's consciousness through the interaction with consumers. This construction process is a kind of production of experience value. This experience process not only gratify consumers, but also improves the public's awareness of product value, and further produces economic benefits. The communication and interaction in the process of online sales consolidate the affective commitment between consumers and producers, so that they can gradually meet the spiritual needs of consumers. Therefore, modern network products have become spiritual products, which use value and sentimental value of consumers can coexist and then to form an experience economy reflecting the emotional and spiritual resonance.

Thirdly, "Digital Maker" is a democratic production based on the sharing economy. In the marketing, producers and consumers co-build a collective wisdom to promote the development of commercial economy. For one thing, consumers' opinions on the improvement of commodities forms an intellectual support. For the other, producers should have the creative spirit to carry out direct production as well as a consciousness about listening to the opinions of consumers. Makers are "innovative, practical, complex, resource accessible, time elastic, interactive, cooperative, and pay attention to sharing"[5]They "go beyond the structure of the production line provided by capitalism, share their ideas through online communities, educate themselves through the Internet, and share global resources through open source" ${ }^{\prime 6]}$. At this time, the economic model of online sales has become a cocreation economy. Commodity production in the online community highlights its sharing. Modern "Digital Maker" should not only master the manufacturing process of products, but also understand the psychological and spiritual needs of consumers by displaying materials, data, finished products and manufacturing process. The model of social development transforms from the traditional competitive mode to cooperative sharing mode--- the combination of human competition and information sharing. All production processes can be viewed through the network platform, and the information of goods can be understood through messages, comments, data ranking and other information. "Digital reproduction art forms the scene of virtual reality through digital reproduction, and then forms the visual landscape and experience effect. With the development of network platform technology, high-definition imaging technology and cloud processing technology, digital information can be transferred in different media, and digital reproduction has formed the form of harmonious symbiosis among technology, art and social ecology." ${ }^{[7]}$ This urges commodity producers to win in the market only by mastering new technologies, new tools, new materials and new processes. "Makers" apply their own unique creativity to go beyond the structure of the production line provided by capitalism. They share their ideas through online communities, educate themselves through the Internet, and share global resources through open source. 


\section{On the Identity Construction and Industrial Development of "Digital Self-Maker" In Online Sales in the Digital Age}

"The concept of sharing has important transformative significance: it has realized the transformation from free competition to cooperative sharing, the transformation from consumerism to shared consumption, and the social improvement from unfair consumption to fair sharing." ${ }^{[8]}$ The network platform itself has the characteristics of democratization. The communication of "Digital Maker" on the network platform help the production tools democratized. At the same time, the protection of the original code also calls for the traditional industrial production technology to form new intellectual property rights and economic value.

\section{EPILOGUE}

The development of network in the digital age creates a virtual network business world for our whole society. In terms of modern design, the first thing is to complete a social design. The works designed by the designer should not only satisfy the purpose of sales, but also to bring meaningful service to consumers. "In the virtual digital world, the "thing" of a commodity has become the link between the intellectual world and the material world. In the private studio of the creator, the product is no longer an abstract idea or a concept only existing in their minds, but a physical product that can be made by hands. "[9]Producers and consumers promote commodity production through online communication and interaction, and build a bridge of the sentimental and spiritual commitment between producers and consumers through online transactions. It can be seen that the "Digital Maker" in the digital age has accomplished a "social design" according to the needs of consumers. This social design reflects a new economic model which is characterized by interaction, experience and sharing in the network economy. In the process of liberating the source code, virtual online sales objectively stimulate the development of industrial economic democracy and the liberation of productive forces.

[Fund Project] quality engineering project of colleges and universities in Anhui Province: provincial key teaching research project

"Research on general education of College Students' human body culture", Project No.: 2018tjyxm2011

\section{REFERENCES}

1) Translated by Xia Yeliang, Lu Wei and Jiang Limei B.JosephII. James H. Gilmore, age of experience economy [M] Taipei: economic news agency, 2011

2) [US] Chris Anderson wrote the long tail theory: why is the future of business a niche market [M] CITIC Publishing Group August 1, 2015

3) [US] Chris Anderson, maker: new industrial revolution [M] CITIC Publishing Group June 20, 2015

4) Merleau Ponty; Jiang Zhihui, translation of phenomenology of perception [M] Commercial Press. 2001-02-01

5) Chris Anderson, translated by Lian Yude The era of self-made [M] Taipei: World Vision 2013

[1] Guanshan The influence of "self maker" movement on the design of cultural and creative products in China [J] Aurora borealis. 2019, P74

${ }^{[2]}$ Zhou rude De, Li Gangyan, current situation and development of digital manufacturing [J] China Mechanical Engineering, 2002 (06): P87-89

${ }^{[3]}$ Wang Youmei, Wang Xiaojing, Bao Xue Becoming a self maker: maker quality and its development in the era of mass entrepreneurship [J] China Audio Visual Education General No.363, P74

${ }^{[4]}$ Wang Liping, Liu Yongliang Artistic concept shift in industrial development in the era of digital reproduction [J] Beauty and creativity of the times, August 2019. P97

${ }^{[5]}$ Keller, J.M Using the ARCS motivational process in computer-based instruction and distance education[J]. New Directions for Teaching and Learning,1999,(78):P37-47.

[6] Liu Yongliang Research on the product extension development and operation mode of Arts and crafts in the Internet era [J] Art life, 2018 (4): P40

${ }^{[7]}$ Wang Liping Concept shift and industrial development in the development of art industry in the digital age [J] Art circles. September 2019,P86

[8] Han Meng Modern meaning, value consideration and socialist trend of sharing concept [J] Northern forum. No. 4, 2017,P32

${ }^{[9]}$ Wang Liping, Liu Yongliang Artistic concept shift in industrial development in the era of digital reproduction [J] Beauty and creativity of the times, August 2019, P97

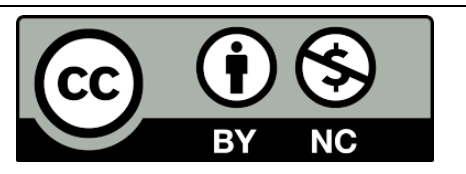

There is an Open Access article, distributed under the term of the Creative Commons Attribution - Non Commercial 4.0 International (CC BY-NC 4.0)

(https://creativecommons.org/licenses/by-nc/4.0/), which permits remixing, adapting and building upon the work for non-commercial use, provided the original work is properly cited. 